\title{
Normative dimensions of lumbar canal and dural sac by computer tomography in Togo
}

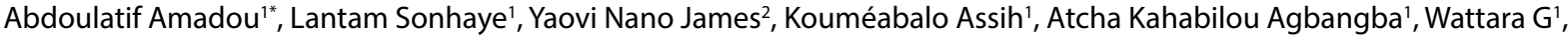 \\ Mazamaesso Tchaou ${ }^{3}$, N'Timon B ${ }^{4}$ and Komlanvi Adjenou ${ }^{1}$
}

*Correspondence: amadoulatif@yahoo.fr

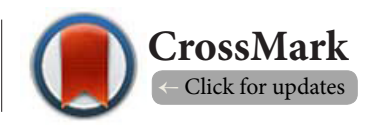

\begin{abstract}
'Department of Radiology, Campus University Teaching Hospital of Lomé, Lomé, Togo.
Department of Anatomy, University of Lomé, Lomé, Togo.

${ }^{3}$ Department of Radiology, Sylvanus Olympio University Teaching Hospital of Lomé, Lomé, Togo.

${ }^{4}$ Department of Radiology, University Teaching Hospital of Kara, Kara, Togo.
\end{abstract}

\begin{abstract}
Objective: To determine through CT scan, the biometrics of the spinal canal and lumbar dural sac of adults in Togo.

Material and method: Twelve month prospective study at Campus Teaching Hospital and Sylvanus Olympio Univesristy Hopsital Center, concerning people over 18 years of age who presented neither any clinical sign nor spinal defect. Distances measured were the antero posterior diameter (APD1) and inner pedicular diameter (IPD) of the lumbar canal, the antero posterior diameter (APD2) and transverse diameter (TD) of the dural sac, followed by the evaluation of APD2/APD1 (R1) and TD/IPD (R2) ratio.

Results: The mean age was 38+/9.34 years. The general average APD of the lumbar canal (APD1) was $15.41 \pm 0.55 \mathrm{~mm}$, with a minimal average of $10.48 \pm 0.57 \mathrm{~mm}$ and a maximal average of $25.00 \pm 2.60 \mathrm{~mm}$. The general average IPD was $23.27 \pm 1.67 \mathrm{~mm}$, with a minimal average of $13.68 \pm 1.46 \mathrm{~mm}$ and a maximal average of $33.68 \pm 1.46 \mathrm{~mm}$. The average APD of the dural sac (APD2) was $11.60 \pm 0.66 \mathrm{~mm}$, with a minimal average of $10.7 \pm 0.66 \mathrm{~mm}$ and a maximal average of $10.7 \pm 0.66 \mathrm{~mm}$. The average TD of the dural sac was $15.55 \pm 1.54 \mathrm{~mm}$, with a minimal average of $14.03 \pm 2.43 \mathrm{~mm}$ and a maximal average of $17.63 \pm 1.82 \mathrm{~mm}$. The evaluation of the ratio $\mathrm{ADP} 2 / \mathrm{ADP} 1(\mathrm{R} 1)$ found general average $\mathrm{R} 1$ of $0.80 \pm 0.04$, with a minimal average $\mathrm{R} 1$ of $0.76 \pm 0.06$ and a maximal average $\mathrm{R} 1$ of $0.85 \pm 0.07$. The ratio $\mathrm{TD} / \mathrm{IPD}(\mathrm{R} 2)$ found an average $\mathrm{R} 2$ of $0.69 \pm 0.14$, with a minimal average of $0.5 \pm 0.12$ and a maximal average of $0.84 \pm 0.08$.
\end{abstract}

Conclusion: The diameters of the lumbar canal and dural sac in Togo do not differ significantly from those described in the literature.

Keywords: Lumbar spinal canal, dural sac, biometrics, computer tomography, Togo

\section{Introduction}

The spinal canal is an osteo-disco-ligamentous duct with a meningeal, neurological, vascular, hydrous and fatty content, which occupies the height of the spine, except for the coccyx. This spinal canal can be narrow congenitally or through arthrosic lesions arising from its strong biomechanical involvement [1]. The lumbar canal stenosis causes the suffering of the vessel wall roots of which intermittent claudication is the most characteristic clinical manifestation [2]. The canal constitutional narrowness can be segmental (L2 to L4), and is often bidirectional, both antero posterior and transversal. Information concerning the precise dimensions of the spinal canal are essential to mention the diagnosis of the constitutional narrow canal and for the spine surgery, hence the importance of imaging (computed tomography and magnetic resonance imaging). Studies about lumbar spinal canal biometrics are rare in sub-Saharan Africa, and the most of those which exist are old and realized through standard X-ray or on sequential scanners. Thus, the normal dimensions used in Africa are those recommended in western countries. We had undertaken this work in order to determine the biometrics of the lumbar canal and the dural sac in Togo, as well as the relations between the lumbar canal and the dural 
Amadou et al. Medical Imaging and Radiology 2017,

http://www.hoajonline.com/journals/pdf/2054-1945-5-3.pdf

sac, what does not almost exist in the literature.

\section{Material and method Study population}

This study was prospective multicenter study that involved two university hospital centers of Togo (University Hospital of Campus, and University Hospital of Sylvanus Olympio) and has been approved by the ethics committees and institutional review boards.

We recruited the consecutive healthy asymptomatic volunteers from January 2015 to December 2015. The inclusion criteria were as follows: patient was healthy, especially without any low back pain actually or in the prior history; age older than 18 years; and signed letter of informed consent.

Exclusion criteria were any of the following: previous trauma, fracture, or surgery of the spine; previous history of low back pain; history of any kind of neurologic symptoms or sensory or motor deficits of the arms; inflammatory disorders; any other severe illness (with continuous pain or reduction of working ability); tumor or metastases of the lumbar; or pregnancy.

All recruited volunteers had to fill out a questionnaire and were examined by a physician to check for exclusion criteria.

\section{Measurement method}

Computed tomography scans were obtained using a General Electric's CT Scan. Sequential 3-mm continuous axial images were obtained parallel to the upper and lower endplates for each vertebra and were studied from $L 1$ to the upper sacrum.

Antero-posterior (APD1) and inter-pedicular (IPD) diameters of the lumbar spinal canal, as well as the antero-posterior (APD2) and transverse diameters (TD) of the dural sac were measured to determine the normal values of these measurements in the normal Togolese population. Then we assessed the ratio of APD2/APD1 (R1) and TD/IPD (R2).

The images were stored in a computerized system that allowed enhancement, magnification, and rotation and had a measuring tool. To measure the distance between 2 points, a cursor is positioned using the mouse over an initial reference point. The cursor is then moved to the second reference point by dragging the mouse. When the mouse button is released, the distance between the 2 points is displayed in the information box, reflecting a measurement from the CT image and the actual size of the lumbar spinal canal and dural sac in the plane of the slice.

Antéro-posterior diameter of lumbar spinal canal (APD1) was defined as the distance between the posterior border of the vertebra and the lamina posteriorly at the midline (Figure 1).

Interpedicular (IPD) distance was measured at the pedicular level as the distance between the inner borders of both pedicles (Figure 1).

Antéro-posterior diameter of dural sac (APD2) was measured between the anterior border and the posterior border of the dural sac (Figure 2), at the same level as the APD1, in order to assess their ratio (R1).

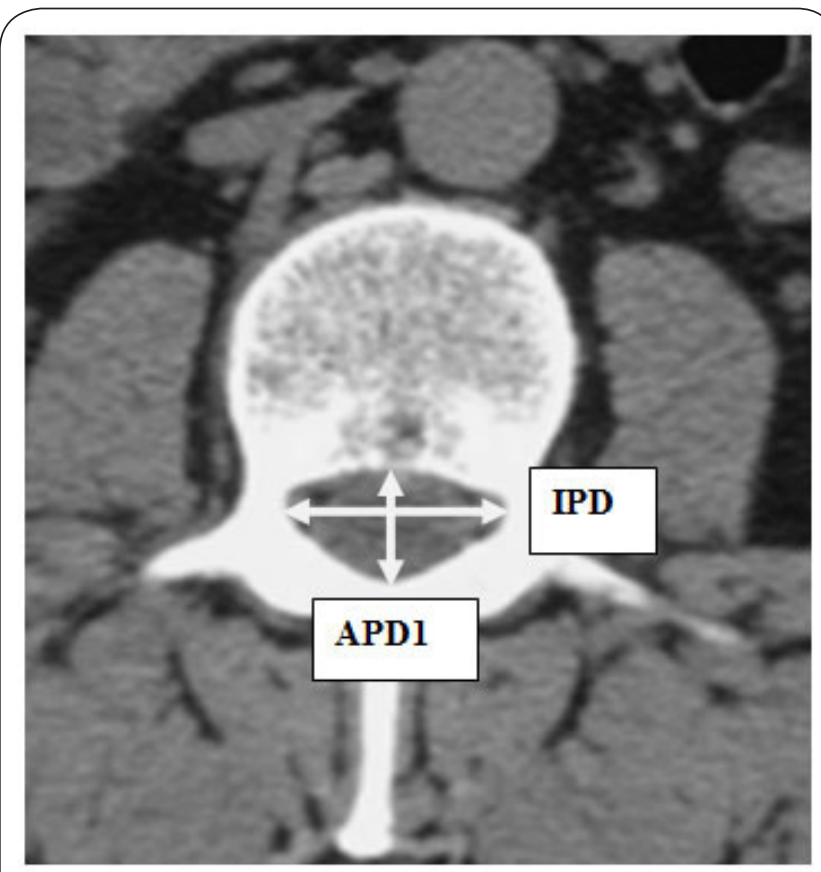

Figure 1. Measurements of anteroposterior diameter (APD1) and interpedicular diameter (IPD) of lumbar spinal canal.

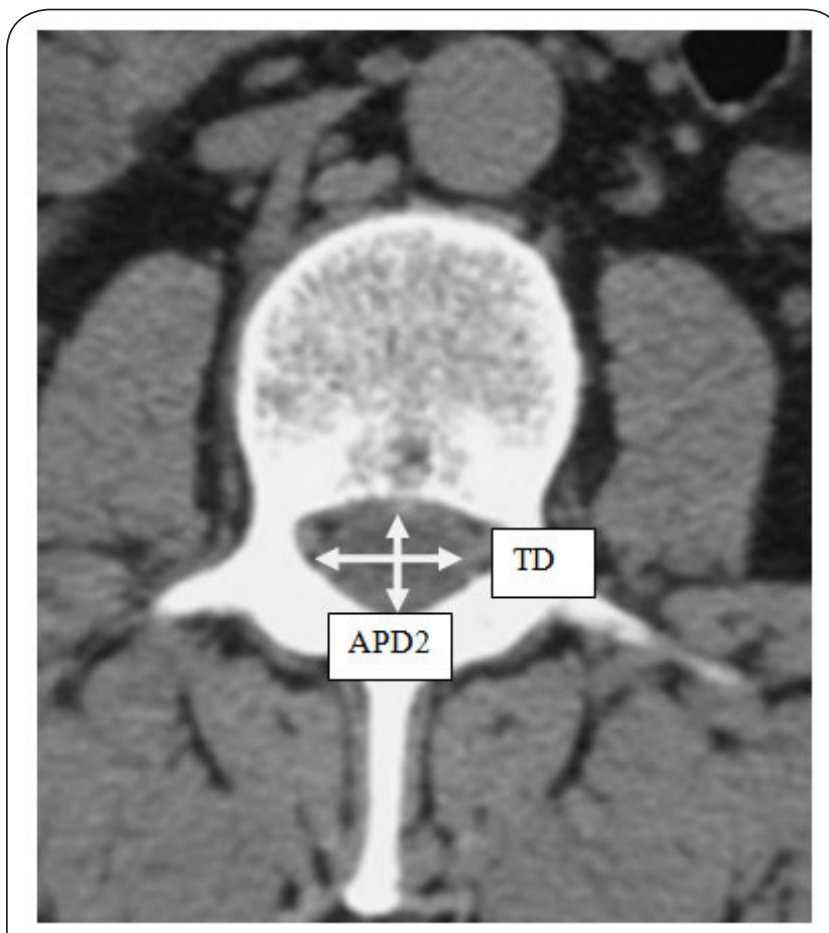

Figure 2. Measurements of anteroposterior diameter (APD2) and transverse diameter (TD) of lumbar dural sac.

Transverse diameter of dural sac (TD) was measured between the right and the left border of the dural sac (Figure 2), at the same level as the IPD, in order to assess their ratio (R2). 
Amadou et al. Medical Imaging and Radiology 2017,

\section{Statistical analysis}

Statistical analysis was performed using the mean, standard deviations, and Chi-square test. A $p$ value less than 0.05 was considered statistically significant.

\section{Results}

Our study was about $500 \mathrm{CT}$ scans of the lumbar. The mean age was $38+/ 9.34$ years. Both sexes were concerned, with 270 (54\%) males against $230(46 \%)$ females.

In general, the average APD of the lumbar canal (APD1) was $15.41 \pm 0.55 \mathrm{~mm}$, with a minimal average of $10.48 \pm 0.57 \mathrm{~mm}$ and a maximal average of $25.00 \pm 2.60 \mathrm{~mm}$. The highest average was noted in L1 $(18.82 \pm 2.14 \mathrm{~mm})$ and the lowest in L3 $(13.47 \pm 1.56 \mathrm{~mm})$ (Table 1).

In general, the average IPD was $23.27 \pm 1.67 \mathrm{~mm}$, with a minimal average of $13.68 \pm 1.46 \mathrm{~mm}$ and a maximal average $33.68 \pm 1.46 \mathrm{~mm}$. We noticed a progressive increase of the average IPD from L1 $(21.35 \pm 2.46 \mathrm{~mm})$ to $L 5(26.71 \pm 4.45 \mathrm{~mm})$ (Table 2).

The average APD of the dural sac (APD2) was $11.66 \pm 0.66 \mathrm{~mm}$, with a minimal average of $10.7 \pm 0.66 \mathrm{~mm}$ and a maximal average of $12.77 \pm 0.66 \mathrm{~mm}$. We noticed a progressive decrease of the average APD of the dural sac from $L 1(12.77 \pm 1.4 \mathrm{~mm})$ to $L 4$ $(10.7 \pm 1.32 \mathrm{~mm})$ and an increase in L5 (11.38 $\pm 1.34 \mathrm{~mm})$ (Table 1).

The average TD of the dural sac was $15.55 \pm 1.54 \mathrm{~mm}$, with a minimal average of $14.03 \pm 2.43 \mathrm{~mm}$ and a maximal average of $17.63 \pm 1.82 \mathrm{~mm}$. The average TD of the dural sac decreased progressively from L1 $(17.63 \pm 1.82 \mathrm{~mm})$ to $\mathrm{L} 5(14.03 \pm 2.43 \mathrm{~mm})$ (Table 2).

The evaluation of the ratio between the APD2 over the APD1 (R1) found general average R1 of $0.80 \pm 0.04$, with a minimal average $R 1$ of $0.76 \pm 0.06$ and a maximal average $R 1$ of $0.85 \pm 0.07$. The $R 1$ decreased progressively from $L 1(0.85 \pm 0.07)$ to L5 $(0.76 \pm 0.06)$ (Table 2).

The ratio of the TD of the dural sac over the IPD (R2) found an average $R 2$ of $0.69 \pm 0.14$, with a minimal average of $0.5 \pm 0.12$ and a maximal average of $0.84 \pm 0.08$. The $\mathrm{R} 2$ decreased progressively from $L 1(0.84 \pm 0.08)$ to $L 5(0.5 \pm 0.12)$ (Table 2).

The comparison of diameters measurements of the lumbar canal and the dural sac, as well as R1 and R2 ratios (distribution of the $p$ value) between male and female did not show statistically significant difference (Table 3 ).

\section{Discussion}

The lumbar canal constitutional narrowness is one of the causes of sciatica. Its diagnosis is done by measuring the lumbar canal dimensions through imaging. The CT has become the most used X-ray means. It makes possible a precise measurement of canal dimensions and the diagnosis of the canal narrowness [3]. It has been the imaging means used in our study. According to a study from ZHOU et al. [4], the interobserver error would be $5 \%$ for the CT.

The APD1 is the main measurement in the evaluation of the canal constitutional narrowness. Our study had found a higher

Table 1. Measures of Antero-Posterior Diameters (APD1) of the lumbar spinal canal and the lumbar dural sac (APD2), and the ratio of the APD2 on the APD1.

\begin{tabular}{|c|c|c|c|c|c|c|}
\hline & \multicolumn{2}{|c|}{ LUMBAR CANAL (APD1) } & \multicolumn{2}{|c|}{ DURAL SAC (APD2) } & \multicolumn{2}{|c|}{ RAPPORT (R1) } \\
\hline & Min - Max & Moyenne & Min - Max & Moyenne & Min - Max & Moyenne \\
\hline L1 & $11.9-26.1$ & $16.05 \pm 1.84$ & $10-14.5$ & $12.77 \pm 1.4$ & $0.74-0.96$ & $0.85 \pm 0.07$ \\
\hline $\mathrm{L} 2$ & $10.4-20$ & $15.26 \pm 1.72$ & $11.2-13.5$ & $12.4 \pm 0.63$ & $0.77-0.88$ & $0.84 \pm 0.03$ \\
\hline L3 & $10-25.1$ & $14.51 \pm 1.97$ & $11-13$ & $11.06 \pm 1.02$ & $0.68-0.95$ & $0.81 \pm 0.07$ \\
\hline L4 & $10.1-23.5$ & $15.09 \pm 2.34$ & $09-13$ & $10.7 \pm 1.32$ & $0.58-0.96$ & $0.76 \pm 0.09$ \\
\hline L5 & $10-30.3$ & $16.16 \pm 2.98$ & $9.5-13$ & $11.38 \pm 1.34$ & $0.67-0.85$ & $0.76 \pm 0.06$ \\
\hline $\begin{array}{l}\text { Moyenne } \\
\text { générale }\end{array}$ & $\begin{array}{l}10.48 \pm 0.5 \\
-25.00 \pm 2.6\end{array}$ & $15.41 \pm 0.55$ & $\begin{array}{l}10.7 \pm 1,49 \\
-12.77 \pm 0.6\end{array}$ & $11.66 \pm 0.66$ & $\begin{array}{l}0.76 \pm 0.66 \\
-0.85 \pm 0.66\end{array}$ & $0.80 \pm 0.04$ \\
\hline
\end{tabular}

Table 2. Measures of the Inter-Pediculaire Diameter (IPD) of the lumbar spinal canal and the Transverse Diameter (TD) of the lumbar dural sac, and the ratio of the TD on the IPD.

\begin{tabular}{lllllll}
\hline & \multicolumn{2}{l}{ LUMBAR CANAL (IPD) } & \multicolumn{2}{l}{ DURAL SAC (TD) } & \multicolumn{2}{l}{ RATIO (R2) } \\
\hline & Min - Max & Moyenne & Min - Max & Moyenne & Min - Max & Moyenne \\
\hline L1 & $15-29.8$ & $21.35 \pm 2.46$ & $14.5-20.5$ & $17.63 \pm 1.82$ & $0.63-0.9$ & $0.8 \pm 0.08$ \\
L2 & $16-31.6$ & $21.72 \pm 2.46$ & $15-18$ & $16.6 \pm 1$ & $0.65-0.95$ & $0.84 \pm 0.03$ \\
L3 & $16-31.6$ & $22.56 \pm 2.65$ & $11.5-17.2$ & $15.27 \pm 2.15$ & $0.68-0.95$ & $0.73 \pm 0.13$ \\
L4 & $11.9-35.9$ & $24.01 \pm 3.47$ & $10-17.4$ & $14.24 \pm 2.22$ & $0.37-0.73$ & $0.58 \pm 0.1$ \\
L5 & $12-45.5$ & $26.71 \pm 4.45$ & $10-17$ & $14.03 \pm 2.43$ & $0.29-0.65$ & $0.5 \pm 0.12$ \\
Moyenne & $13.68 \pm 1.4$ & $23.27 \pm 1.67$ & $14.03-17.63$ & $15.55 \pm 1.54$ & $0.5-0.84$ & $0.69 \pm 0.14$ \\
générale & $-33.68 \pm 1.5$ & & & & & \\
\hline
\end{tabular}


Amadou et al. Medical Imaging and Radiology 2017,

http://www.hoajonline.com/journals/pdf/2054-1945-5-3.pdf

doi: $10.7243 / 2054-1945-5-3$

Table 3. Comparison of the APD1 and the IPD of the cervical spinal canal, the APD2 and the TD of the cervical spinal cord, the ratio $R 1$ and the ratio $R 2$ between male and female patients (division of P-values).

\begin{tabular}{lllllll}
\hline & \multicolumn{2}{l}{ CANAL LOMBAIRE } & \multicolumn{2}{c}{ SAC DURAL } & \multicolumn{2}{l}{ RAPPORTS } \\
& APD1 & IPD & APD2 & TD & R1 & R2 \\
\hline L1 & 0.93 & 0.86 & 0.26 & 0.26 & 0.44 & 0.26 \\
L2 & 0.86 & 0.97 & 0.40 & 0.69 & 0.30 & 0.34 \\
L3 & 0.84 & 0.95 & 0.70 & 0.18 & 0.44 & 0.35 \\
L4 & 0.89 & 0.96 & 0.52 & 0.44 & 0.44 & 0.35 \\
L5 & 0.92 & 0.96 & 0.48 & 0.35 & 0.44 & 0.26 \\
\hline
\end{tabular}

P-values are higher than 0.05: absence of statistically significantly difference of diameters and the ratio between the male and female sex.

value of the average APD1 in L1 and L2. The lower value was found in L3. The same remark was made by Amonoo-Kuofi et al. [5] in Nigeria, by Tarek Aly et al. [6] in Egypt, and by Lee et al. [7] in Corea. The high APD in L1 and L2 could be explained by the bulge of the conus medullaris at this level. The study of El-Rakhawy et al. [8] in Pakistan found higher values in L4 and L5 and the lowest value in L3. Thus, many studies [5-8] agree on the fact that the smallest measurement of the APD is in L3. Statistically, there was no significant difference of the APD between male and female in our study. The same remark was made by El-Rakhawy et al. [8] in Pakistan. The comparison of the dimensions of our study with those of Amonoo-Kuofi et al. [5] in Nigeria, of Ongolo Zogo et al. [9] in Cameroon, of Tarek et al. [6] in Egypt, and of El Rakhawy et al. [8] in Pakistan and with that of Getroa [10] in Belgium did not find significant difference statistically. But our study found significant difference statistically in APD1 measurements with the study of Lee et al. [7] in Korea. The APD would be similar between the Blacks, the Arabs, and the Whites, and would differ between the Blacks and the Koreans. But according to the study of Eisenstein [11], there would be a difference of the APD of the lumbar canal between the Blacks and the Caucasians of South Africa.

Concerning the IPD, our study showed a progressive increase from L1 to L5. Tarek et al. [6] and Ongolo Zogo et al. [9] found respectively in Egyptians and in Cameroonians similar results. On the other hand, El-Rakhawy et al. [8] noticed an average IPD almost identical at the level of the four first lumbar vertebrae $(\approx 24 \mathrm{~mm})$ followed by an increase in L5 $(28.48 \mathrm{~mm})$. The comparison of the IPD between our study and those of Ongolo Zogo et al. [9] in Cameroon, of Amonoo-Kuofi et al. [12] in Nigeria, of Tarek et al. [6] in Egypt, of El-Rakhawy M et al. [8] in Pakistan did not show any significant difference statistically. But on the other hand, the studies of Postachini et al. [13] and of Piera et al. [14] showed that the IPD would be different across populations. The IPD of Egyptians would be different from that of Saudis and Americans. The IPD of Egyptians is larger than that of Nigerians and South Africans and smaller than that of Spaniards. Our study did not statistically found significant difference of the IPDs of the lumbar canal between male and female. This is similar to the study of El-Rakhawy et al. [8].

We evaluated in our study the antero-posterior diameter of the dural sac (APD2), with a decrease from $L 1$ to $L 4$, and increase in L5. Few studies evaluated the APD of the dural sac. The study of Getroa [10] performed the measurements at the disc level, and found a progressive decrease from L1-L2 to L5-S1.The comparison of dimensions of our study with those of Getroa [10] did not find statistically significant difference. Statistically, there was no significant difference of the APDs of the dural sac between male and female.

The study of the transverse diameter of the dural sac (TD) in our study found a progressive decrease from L1 to $L 5$. The studies that evaluated in the literature the TD of the dural sac are rare.

All in all, the canal narrowness would be associated with the relations between the lumbar canal and the dural sac, whether in the antero posterior plan or the transverse one. Our study thus evaluated these relations. In the antero posterior plan, the ratio (R1) varied between 0.76 and 0.85 and in the transverse plan, the ratio (R2) varied between 0.5 and 0.84 . These two ratios decreased progressively from $L 1$ to $L 5$. The studies that evaluated the relations between the dural sac and the lumbar canal are very few. However the narrow lumbar canal would result from the fact that the size of the dural sac is inadequate to that of the lumbar canal. According to the studies of Geisser et al. [15], in normal conditions, there is an empty space between the lumbar canal and its content, enabling free movement of the content, without tension or pressure during movement of the lumbar spine. An abnormal reduction of this empty space between the lumbar canal and its content would be the cause of the nervous suffering.

\section{Conclusion}

Dimensions of the lumbar canal and the dural sac in Togo are similar to those described in Arab and Western countries. The lower APD of the lumbar canal would be in L3. The IPD of the lumbar canal, the APD and TD of the dural sac would progressively decrease from L1 to L5.

\section{Competing interests}

The authors declare that they have no competing interests.

\section{Authors' contributions}

\begin{tabular}{|l|c|c|c|c|c|c|c|c|c|}
\hline Authors' contributions & AA & SL & JYN & AK & AAK & WG & TN & NB & AK \\
\hline $\begin{array}{l}\text { Research concept and } \\
\text { design }\end{array}$ & $\checkmark$ & $\checkmark$ & $\checkmark$ & $\checkmark$ & $\checkmark$ & $\checkmark$ & $\checkmark$ & $\checkmark$ & $\checkmark$ \\
\hline $\begin{array}{l}\text { Collection and/or } \\
\text { assembly of data }\end{array}$ & $\checkmark$ & $\checkmark$ & $\checkmark$ & $\checkmark$ & $\checkmark$ & $\checkmark$ & $\checkmark$ & $\checkmark$ & $\checkmark$ \\
\hline $\begin{array}{l}\text { Data analysis and } \\
\text { interpretation }\end{array}$ & $\checkmark$ & $\checkmark$ & $\checkmark$ & $\checkmark$ & $\checkmark$ & $\checkmark$ & $\checkmark$ & $\checkmark$ & $\checkmark$ \\
\hline Writing the article & $\checkmark$ & $\checkmark$ & -- & -- & -- & -- & -- & -- & -- \\
\hline $\begin{array}{l}\text { Critical revision of the } \\
\text { article }\end{array}$ & $\checkmark$ & $\checkmark$ & -- & -- & -- & -- & -- & -- & - \\
\hline Final approval of article & $\checkmark$ & $\checkmark$ & $\checkmark$ & $\checkmark$ & $\checkmark$ & $\checkmark$ & $\checkmark$ & $\checkmark$ & $\checkmark$ \\
\hline
\end{tabular}


Amadou et al. Medical Imaging and Radiology 2017,

http://www.hoajonline.com/journals/pdf/2054-1945-5-3.pdf

Publication history

Senior Editor: Domenico Rubello, Santa Maria della Misericordia

Hospital, Italy.

Received: 27-Jun-2017 Final Revised: 31-Jul-2017

Accepted: 07-Aug-2017 Published: 23-Aug-2017

\section{References}

1. Spencer DL, Irwin GS and Miller JA. Anatomy and significance of fixation of the lumbosacral nerve roots in sciatica. Spine (Phila Pa 1976). 1983; 8:672-9. | PubMed

2. Verbiest $H$. Lumbar spinal stenosis. In: Youngman's Neurological Surgery: Comprehensive References Guide to the Diagnosis and Management of Neurosurgical Problems. 3rd ed. Philadelphia: Saunders. 1990; 2805-55.

3. Ullrich CG, Binet EF, Sanecki MG and Kieffer SA. Quantitative assessment of the lumbar spinal canal by computed tomography. Radiology. 1980; 134:137-43. | Article | PubMed

4. Zhou SH, McCarthy ID, McGregor AH, Coombs RR and Hughes SP. Geometrical dimensions of the lower lumbar vertebrae--analysis of data from digitised CT images. Eur Spine J. 2000; 9:242-8. | Article | PubMed Abstract | PubMed FullText

5. Amonoo-Kuofi HS. The sagittal diameter of the lumbar vertebral canal in normal adult Nigerians. J Anat. 1985; 140 ( Pt 1):69-78. | PubMed Abstract I PubMed FullText

6. Aly T and Amin O. Geometrical dimensions and morphological study of the lumbar spinal canal in the normal Egyptian population. Orthopedics. 2013; 36:e229-34. | Article | PubMed

7. Lee HM, Kim NH, Kim HJ and Chung IH. Morphometric study of the lumbar spinal canal in the Korean population. Spine (Phila Pa 1976). 1995; 20:1679-84. | PubMed

8. El-Rakhawy M, El-Shahat AR, Labib I and Abdulaziz E. Lumbar vertebral canal stenosis: concept of morphometric and radiometric study of the human lumbar vertebral canal. Anatomy. 2010; 4:51-62. | Pdf

9. Ongolo Zogo P, Mvogo Minkala LT and Juimo AG. Biometrie canographique du canal rachidien lombaire de l'adulte camerounais. $J$ Afr Imag Méd. 2011; 6:308-317.

10. Malghem J, Lecouvet F, Willems X, Vande Berg B, Laredo JD, Bousson $V$. Dimensions normales du canal rachidien lombaire " Etude du GETORA ». in F Lecouvet, Ph Goupille, P Guigui, A feydy, T Moser, M Wybier : « Le rachis » GETROA Opus XXXV, Sauramps Medical Montpellie. 2008 ; 147-155.

11. Eisenstein $\mathrm{S}$. The morphometry and pathological anatomy of the lumbar spine in South African negroes and caucasoids with specific reference to spinal stenosis. J Bone Joint Surg Br. 1977; 59:173-80. | Article | PubMed

12. Amonoo-Kuofi HS. Maximum and minimum lumbar interpedicular distances in normal adult Nigerians. J Anat. 1982; 135:225-33. | PubMed Abstract | PubMed FullText

13. Postacchini F, Ripani $M$ and Carpano S. Morphometry of the lumbar vertebrae. An anatomic study in two caucasoid ethnic groups. Clin Orthop Relat Res. 1983; 296-303. | PubMed

14. Piera V, Rodriguez A, Cobos A, Hernandez R and Cobos P. Morphology of the lumbar vertebral canal. Acta Anat (Basel). 1988; 131:35-40. | PubMed

15. Geisser ME, Haig AJ, Tong HC, Yamakawa KS, Quint DJ, Hoff JT, Miner JA and Phalke VV. Spinal canal size and clinical symptoms among persons diagnosed with lumbar spinal stenosis. Clin J Pain. 2007; 23:780-5. | Article | PubMed

Citation:

Amadou A, Sonhaye L, James YN, Assih K, Agbangba AK, G W, Tchaou M, B NT and Adjenou K. Normative dimensions of lumbar canal and dural sac by computer tomography in Togo. Med Imaging Radiol. 2017; 5:3. http://dx.doi.org/10.7243/2054-1945-5-3 